\title{
EARTHQUAKE INSURANCE LOSS ASSESSMENTS FOR REGIONS OF AUSTRALIA
}

\author{
R B Shephard ${ }^{1,4}$, E G C Smith ${ }^{2,4}$, D D Spurr ${ }^{3,5}$
}

\begin{abstract}
SUMMARY
Following the Newcastle earthquake of December 1989, a consortium of Australian insurance companies commissioned Works Consultancy Services Ltd, New Zealand to undertake earthquake probable maximum loss assessments for the main city centres of Australia. Studies have been completed for the regions around Sydney, Melbourne, Adelaide, Perth and Brisbane. Customised insurance loss assessment models were developed for each study region, with each including specific analytical models for geography, seismicity, ground conditions, patterns of building construction, and insurance company exposures. The analysis model includes earthquake insurance loss versus shaking intensity relationships derived from Australian and international data, and takes specific building vulnerabilities into account. Loss assessments target the Probable Maximum Loss in relation to return period.
\end{abstract}

\section{INTRODUCTION}

Coinciding with the occurrence world wide of natural disasters of earthquake and hurricane, the December 1989 Newcastle earthquake insurance losses focused attention on reinsurance for catastrophe losses. The Newcastle earthquake, following the earlier Tennant Creek (1988), Meckering (1968) and Adelaide (1954) events, alerted insurers to the need for better quantification of their Australian earthquake exposures. Subsequent heavy world wide catastrophe insurance losses sustained by international reinsurers accelerated demands for better risk quantification and sharply increased the cost of reinsurance.

Works Consultancy Services had been developing earthquake loss assessment methodologies since 1984 and had carried out studies for various New Zealand insurance companies. On the basis of this work, counterpart insurance companies commissioned earthquake loss assessments in Australia, starting with the Sydney Region in 1990. Subsequent studies have since been completed for all main Australian cities.

A customised computerbased analytical model for the Probable Maximum Loss (PML) evaluation of insured earthquake risks was established for each region, and coupled with the insurance data provided, independent PML estimates were assessed for each company. Outputs of the evaluations have been directed towards insurance industry needs. PML assessments were determined on a probabilistic basis ranking the estimated loss against return periods ranging from 100 to 1000 years. The main features of the method and database used in the PML assessment model are described following, together with presentation of indicative loss results.

Works Consultancy Services Ltd, Wellington, New Zealand

Victoria University of Wellington, New Zealand

Spurr Consulting Services, Wellington, New Zealand

4 Fellow

5 Member
Specific objectives and achievements of the projects undertaken include:

- Better quantification of each company's earthquake risk exposure.

- Consistent determination of earthquake risk for all regions and companies.

- Providing credible quantified information that can be used as a basis for developing risk management strategies and for negotiations with reinsurers.

- Acceptance of the methodology and results by international reinsurers.

\section{TARGET LEVEL OF CONFIDENCE}

In consultation with the client insurance companies, it was agreed that the PML procedures be aimed at providing a "90 percentile" estimate of the losses expected under given scenario conditions. Thus in 9 out of 10 events the actual total loss is not expected to exceed the estimated value.

In practice the limited amount of historical seismicity and vulnerability data directly applicable to Australia made a formal probabilistic evaluation impossible. Hence the "90 percentile" was a nominal target, with allowances for uncertainty and variability necessarily based on expert judgement.

To avoid compounaing margins, hazard parameters were assessed as "cautious mean values", while the vulnerability models were based on "high" or nominal 90 percentile estimates. An additional overall margin was applied to allow for uncertainty in the risk data supplied and in components not specifically considered. 


\section{RETURN PERIOD}

In high seismicity areas, the events considered in PML evaluations tend to be close to "worst case" earthquake scenarios. Low seismicity areas are characterised by a much lower frequency of earthquakes, but the maximum magnitude of earthquake that can occur may not be much less than in many high seismicity areas. Under these conditions it is inappropriate to base PML's on "worst case" scenarios as the probability of these occurring is extremely low. PML estimates are therefore usually calculated in terms of a specified return period or exceedance probability. In the Australian projects, estimates were obtained for several different return periods allowing a continuous relationship between PML and return period to be plotted over the range from 100 to $1000+$ years. Final choice of return period is a commercial decision made by each insurer. The overall risk level targeted ( $90 \%$ probability of nonexceedance over the return period) is intended to provide a balance between risk of ruin from a large loss in any event, and excessive cost of re-insurance.

\section{LOSS ACCUMULATION GEOGRAPHIC MODEL}

To ensure that all significant sources of seismicity and concentrations of risk exposure were included, loss accumulation areas of $300 \mathrm{~km}$ to over $700 \mathrm{~km}$ radius were established around the main city in each region. Such large accumulation areas are necessary for areas of low and dispersed seismicity to ensure that all losses from modelled earthquakes are included. A digitised geographic model differentiating characteristics of hazard and exposure, using 700 or more postcodes per region, was used in the analyses. Postcodes within each region were assigned to different "building characteristic groups" on the basis of field observation and from reviews of historical planning data and various historical maps. The field observations also identified characteristic building styles and earthquake vulnerabilities; eg irregular shapes and foundations.

\section{RISK EXPOSURE DATA}

Each insurance company provided its risk exposure data in the form of portfolio profiles and a sample survey of risks. The portfolio data were provided for each of four risk classes: domestic, residential strata title, commercial and industrial material damage, and business interruption. The data for each region were presented in sum insured value bands for each postcode within the project accumulation area. The sum insured bands were used as a grouping of risk "size" and hence of certain vulnerability characteristics. Sub-dividing exposures by postcode and sum insured band minimised the risk of the estimates being biased by the vulnerabilities of atypical high value risks and enabled more specific analysis.

A sample of insured risks was selected for specific site survey to better establish the type and characteristics of the property insured by each company. The survey samples were randomly selected based on a specification prepared from analysis of the portfolio profiles, and were intended to be representative of the whole exposure.

Depending on the spread of risks insured, some 100 to 250 domestic and 100 to 150 commercial and industrial risks were surveyed by each company, in each region. In some circumstances the survey data were shared between the companies, eg domestic risks combined to give a more substantial sample and co-insured commercial and industrial risks identified and included in the surveys for each relevant company.

The site surveys provided insurance policy details and earthquake damage characteristics for the selected risks. Details obtained included the risk location by address and postcode, sums insured for building, contents, business interruption, excess, and net percentage of exposure retained by the insurer. Building characteristics included type or function, number of storeys, area, year built, construction material and form, and specific vulnerability details such as soil zone, condition, form irregularity, potential pounding from adjacent structures, chimneys, parapets, gables and roof construction, etc. Facade and contents classifications were also recorded.

The site surveys were carried out by insurance company staff or consultants after two days of training sessions and field review.

\section{SEISMIC HAZARD}

Seismic Hazard describes the intensities and frequency of earthquake induced ground shaking and other damaging phenomena expected at a site. Seismic hazard comprises three principal components: regional seismicity, attenuation, and local site characteristics and hazards. Generally attenuation and local site characteristics are constant over time but regional seismicity, and particularly the frequency of earthquakes at damaging magnitudes, can vary by a factor of 10 or more over a period of a few decades. Given the potential consequences of a company's losses exceeding the amount of reinsurance carried, there was a need for prudent caution in estimating the appropriate level of seismicity.

Reinsurance contracts are renewed annually and many factors impact on the availability and cost of cover. The threat to the reinsurance levels held by primary insurers in the current and next few years over which the PML estimates will apply, is therefore the short term rather than long term seismic hazard level.

\section{Seismicity}

Regional seismicity is determined by the locations of seismically active zones and the magnitude, frequency and characteristics of source events originating in each zone. In all regions the estimates of seismicity were based on limited and probably incomplete data, with some regions better served by instrumentally recorded data than others. Therefore, while it is generally accepted that the near future seismicity is usually better forecast by the recent past activity than by the long term average seismicity, due caution was applied as appropriate for regional situations.

For the purposes of modelling seismic risk, the region within the accumulation area was divided into several seismicity zones with different rates of activity (Figure 1). The seismicity of each zone was modelled according to the general Gutenberg and Richter relationship

$$
\mathrm{N}=\mathrm{N}_{\mathrm{o}}\left[10^{-\mathrm{b} \cdot \mathrm{M}}-10^{-\mathrm{b} \cdot \mathrm{Mmax}}\right]
$$

where $\mathrm{N}$ is the number of earthquakes exceeding magnitude $\mathrm{M}$ per annum per $10,000 \mathrm{~km}^{2}, \mathrm{~N}_{0}$ is the value of $\mathrm{N}$ at zero magnitude $(\mathrm{M}=0.0), \mathrm{b}$ is a parameter defining the change in frequency of earthquakes with magnitude, and Mmax is the 


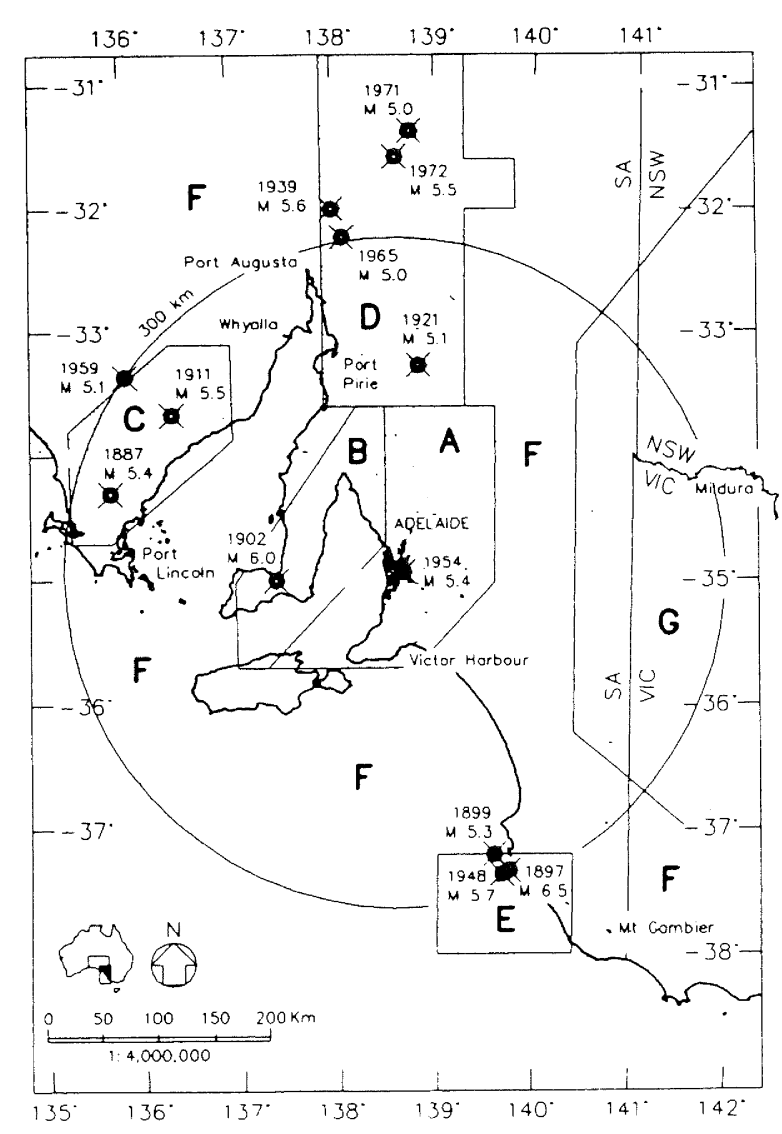

FIGURE 1 Seismicity zones modelled for the Adelaide region

estimated maximum earthquake magnitude for the region. Different rates of activity $\left(\mathrm{N}_{\mathrm{o}}\right)$ were modelled for each zone, but generally there were not sufficient data to determine separate values of $b$.

\section{Sydney Seismicity}

Seismicity of the Sydney region was found to be dominated by earthquakes sourced in three relatively localised areas: the Dalton-Gunning region to the south west of Sydney, Newcastle to the north of Sydney, and the coastal area immediately to the south-west of Sydney itself. The recent level of seismic activity in the Sydney - Newcastle region has been higher than the historical average with four $M_{L} 5.3$ - 5.6 earthquakes during the past 35 years $(1961,1973,1989$ and 1994) as opposed to only two $\mathrm{M}_{\mathrm{L}} 5.3$ earthquakes during the preceding 100 years (both the latter in the vicinity of Newcastle). Emphasis was therefore placed on modelling the more recent rates of earthquake activity.

\section{Melbourne Seismicity}

Melbourne seismicity was found to be mainly concentrated in a band about $210 \mathrm{~km}$ wide containing Melbourne. Since 1885 there does not appear to have been any significant period of increased or decreased seismicity except for an active period c. 1960 -c. 1971.

The PML estimate was found to be sensitive to variations within the error bounds of the derived seismicity parameters. Across the full range of values considered there was a factor of 6.6 change in the estimated PML. In view of the high sensitivity of the results to the model parameters, a "cautious" estimate based on the 67 percentile was considered more appropriate than a model based on the straight mean of the historical data.

\section{Adelaide Seismicity}

Despite Adelaide's reputation as an area of "high" seismic risk, investigations showed that the historical seismicity within 200 $\mathrm{km}$ of Adelaide City has been very low. There have been only three magnitude 5 or larger earthquakes in this area in the last 110 years. The majority of seismic activity in recent times has occurred further north in the Flinders Ranges. Because of its distance from Adelaide, that activity contributes little to the regional PML estimates.

With the short historical record available and low level of seismic activity, there is significant uncertainty in the seismic hazard assessment. While the conventional Gutenberg and Richter model was satisfactory in matching the observed seismicity, there was a concern that the location of the 1954 earthquake very close to the city in an area where there are large faults, could indicate a potential for future local events. Evidence of Quaternary movements of these faults has been inferred from differences in sedimentation [7, 8]. Although seismological evidence suggested a lower level of hazard, it was deemed prudent to consider that the city area could be subject to more events similar to that of 1954. A two tier modelling of seismicity was therefore adopted for the Adelaide PML estimate; the Gutenberg and Richter model and a simulation of the 1954 earthquake. The 1954 earthquake scenario was found to govern estimates of PML for return periods less than about 600 years.

\section{Perth Seismicity}

The seismic risk in the Perth region is dominated by two seismicity zones; the "Perth" zone and the "Meckering" zone. Both zones are oriented approximately north-south. The "Perth" zone covers the area in the immediate vicinity of Perth City and extends from c. $100 \mathrm{~km}$ offshore in the west, to about $50 \mathrm{~km}$ inland in the east. This zone has been almost aseismic in historical times and the small and moderate magnitude local earthquakes contribute little to the seismic risk of the region. By contrast, the adjacent "Meckering" zone to the east of Perth has been one of the most active areas in Australia since at least the 1960's. The $\mathrm{M}_{\mathrm{L}} 6.9$ Meckering earthquake occurred in this zone in 1968 and is still the second largest historical earthquake on the Australian continent. The epicentre of the earthquake was only $115 \mathrm{~km}$ east north-east of the Perth Central Business District. The $1979 \mathrm{M}_{\mathrm{L}} 6.2$ Cadoux earthquake was centred about $180 \mathrm{~km}$ north-east of Perth and is another important event in the "Meckering" zone. The largest historical earthquake on land in Australia, the $1941 \mathrm{M}_{\mathrm{L}} 7.2$ Meeberrie earthquake, was located in a sparsely populated area about $400 \mathrm{~km}$ north of Perth.

In the case of the "Meckering" seismicity zone, the depths of earthquakes and attenuation of strong shaking appear to be different for most, but not all events in the zone. Two separate types of concurrent seismic activity were therefore modelled a background activity of normally attenuating earthquakes occurring at the same rate as for the coastal zone, and the majority of the activity consisting of shallow depth earthquakes attenuating relatively quickly to give lower shaking intensities outside the immediate epicentral area. 


\section{Brisbane Seismicity}

The rate of earthquake activity in the Brisbane region is the lowest of any region in Australia that includes a major city. The most active zone is in the area between about $100 \mathrm{~km}$ and $300 \mathrm{~km}$ north of Brisbane, extending from the coast to about $250 \mathrm{~km}$ inland. There is some indication that the relatively high rate of activity early this century has now diminished.

\section{Relative Seismicity}

Seismicity models for selected zones in each of the study regions are compared in Figure 2.

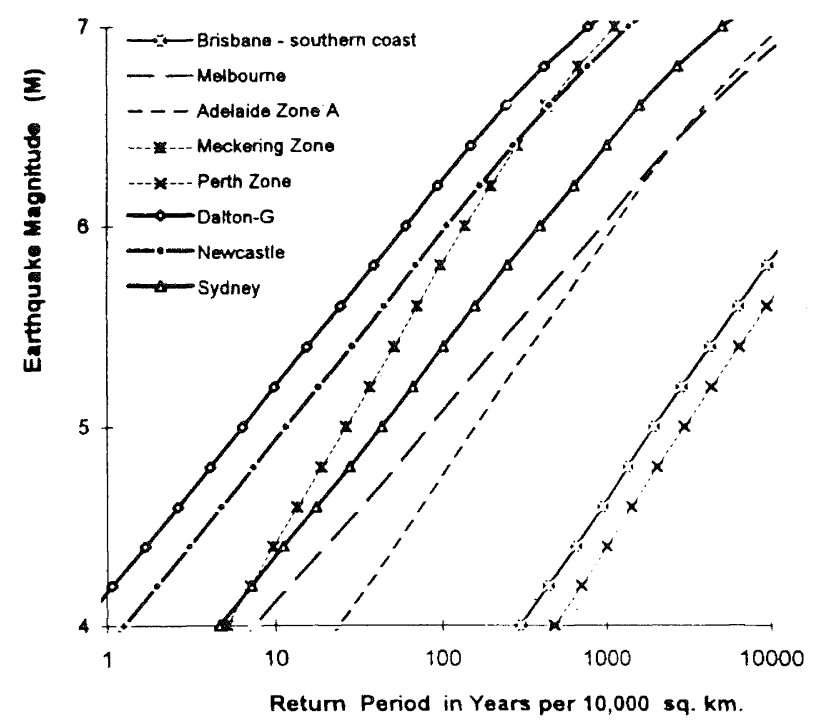

FIGURE 2 Comparison between seismicity models for each region

\section{Attenuation of Strong Shaking}

The attenuation function relates the variation of earthquake ground shaking intensity with distance from the source of an earthquake. Factors influencing attenuation include the source characteristics of the earthquake, the intervening geology and the local ground conditions. For the purposes of these studies, the variation in Modified Mercalli intensity was used as the measure of ground motion. The models used in the studies were based the commonly adopted function:

$$
\mathrm{I}_{\mathrm{MM}}=\mathrm{a}+\mathrm{bM}-\mathrm{c} \cdot \log _{10} \mathrm{R}
$$

where $a, b$ and $c$ are variables determined to suit each zone of each region, and $\mathrm{R}$ is the hypocentral distance [3]. The adopted relationships make separate allowance for increased intensity of ground shaking due to local areas of soft soils.

Studies showed that the PML estimates can be particularly sensitive to the modelled attenuation. Generally in any region there were too few historical instances of higher Modified Mercalli (MM) intensities to determine independent regional attenuation functions over all intensities. A cautious approach was taken, giving emphasis to levels of ground motion expected to contribute most to the PML estimates, eg intensities in the range MM VI to MM VIII. Due care was also given to determining the severity of shaking close to the earthquake epicentre, especially for moderate shocks, which have small regions of damage close to the earthquake source.

The attenuation relationships were developed based on Australian earthquakes where adequate data existed and tested using comparisons with larger New Zealand and Californian earthquakes. The resulting relationships generally fit within the scatter of available Australian intensity data, particularly when allowance is made for amplification effects of soft soils, and are reasonably conservative for events larger than magnitude 7 , for which local data are lacking.

Except for modelling the Meckering zone near Perth, all probabilistic PML estimates were based on an assumed average earthquake depth of $10 \mathrm{~km}$. Any effect on the PML estimates from this assumption is minimised because most of the modelled earthquake sources are located outside the densely populated areas.

For the Meckering zone "Meckering type" activity, a focal depth of about $6 \mathrm{~km}$ was indicated, based on reported focal depth determinations. However a shallower depth (closer to the average depth of rupture) was modelled for the PML estimates in order to better simulate the observed intensities in the immediate epicentral region.

\section{Soft Soil Amplification}

Soft soil areas comprise flexible or low strength cohesive soils or less dense cohesionless soils. Generally these are late Quaternary deposits comprising river, marine, estuarine or swamp materials in unconsolidated form.

These soils commonly exhibit amplified ground shaking under moderate to strong earthquake shaking, one, two or more increments of intensity higher than adjacent areas of firm ground.

The extent of soft soil areas modelled for each region was determined from 1:50,000 to 1:250,000 scale geologicai maps according to availability. The characteristics of the mapped soils were assessed from informal discussions with engineers and geologists of government departments, territorial authorities, research organisations, or consulting practices. Soil depth data were difficult to obtain for most regions but where data were available, a minimum c. $10 \mathrm{~m}$ depth was generally adopted for defining the extent of soft soil areas.

The amplifying effect of soft soils, while being well documented, is difficult to quantify. Damage effects include increased intensities of shaking, co-resonance between the period range of the ground and the buildings on it, and reflection and magnification patterns from the underlying geology. The model adopted assumes a single value of increment of $+1 \mathrm{MM}$. This simple approach applies only to the assessed proportion of developed areas on soft ground within each postcode, and is intended to represent the mean effect for the range of soils and classes of buildings in the area

\section{Permanent Ground Deformations}

Permanent ground deformations such as liquefaction, slumping, differential settlement, landslides, rockfalls etc, can be an added source of damage in some areas. The ground deformation hazards associated with soft ground areas were assumed to have 
been allowed for as part of the general soft ground penalty. In the Australian context, landslides and rockfalls were considered to have a minor effect compared to other hazards.

\section{RISK VULNERABILITY}

\section{Effect of Australian Conditions}

Earthquake loss vulnerabilities for buildings and other types of risks were assessed wherever possible specifically for Australian conditions. This was important for several reasons:

- Australia's generally low seismicity means that very few buildings are constructed to earthquake resistant criteria. Construction practices differ from those in higher seismicity areas for which earthquake loss data are available. Widely used forms of construction in Australia include unreinforced cavity (or double) brick and irregular structural configurations, which have higher vulnerability than regular buildings.

- The type of building construction and lower seismicity in Australia mean that earthquake loss assessments are critical at lower shaking intensities. In areas of high seismicity, damage at MM VI - MM VII shaking intensities contributes little to the total losses expected under probable maximum conditions. Consequently less emphasis has been placed on the accuracy of risk vulnerabilities for low intensity shaking.

- Many of the published earthquake damage data were based on visual assessments or estimates of damage rather than insurance losses. Often there are significant differences, particularly for masonry construction where buildings with apparently slight exterior damage can be constructive total losses.

- In Australia replacement value earthquake cover is generally included with fire insurance cover at no additional cost and consequently is almost universal. In addition deductibles are generally very low, approximately $0.2 \%$ for dwellings and generally $1 \%$ down to less than $0.1 \%$ on large commercial and industrial risks.

Specific studies were undertaken to determine the vulnerability relationships appropriate to Australian seismicity levels, construction types and earthquake insurance conditions. These focused on the more common construction types while vulnerabilities for other risk types were generally based on published data.

\section{Inter-Event and Inter-Company Variability of Losses}

Inter-event variability of earthquake insurance losses is a critical factor in determining the target 90 percentile vulnerability estimates. Variations in the average losses for a particular intensity arise from a variety of sources. These include inconsistencies of assigning MM intensities, variations in the mean vulnerabilities for each risk class and variations in the characteristics of ground shaking from event to event, as well as "chance" effects such as the extent of post-earthquake fires and weather conditions preceding, during and after each event. In addition, there can be significant variations between individual insurers. This is in part "company culture" related, but includes a component of inter-event variability, which is a function of sample size. Sample size effects can be significant where individual companies insure only a few percent of the affected risks.

The loss experience of two or three companies in a single earthquake cannot be assumed to indicate "typical average" vulnerabilities. Consequently the margins applied must recognise uncertainly in the historical data as well as potential variability of future losses. For example, there were no significant fires caused by the Newcastle earthquake, which was possibly a function of the weather conditions and timing of the event (mid morning on a fine summers' day during the Christmas holiday period). There is also little doubt that the number of deaths and consequently impact of emergency and relief operations could have been much higher had the earthquake occurred on a normal working day during the school term. A much higher death toll could have significantly impacted the timing and standard of repairs and reconstruction permitted.

Insufficient data were available to enable confident assessment of inter-event variability of losses. Most published vulnerability data were for broad risk categories, often based on selected (and possibly biased) samples. The basis of analysis and source of the data were often not clearly identified, making it impossible to isolate the effects of inter-event variability. Some guidance was obtained by comparing the ATC-13 [6] "high" and "mean" damage ratio estimates. These differ by a factor of about 2 at low to moderate MM intensities. The standard error term in MM intensity attenuation relationships also provides some indication of the variability of losses (since MM intensity is in part based on assessment of earthquake damage). This term is commonly of the order of $0.4 \mathrm{MM}$, which corresponds to a 90 percentile damage ratio of approximately 2 times the mean value.

Initial evaluations of Newcastle loss data obtained from two insurers showed that after gross differences in portfolio were allowed for, there was a factor of up to 2 variation between the average losses sustained by the companies. Subsequent analysis undertaken by the Insurance Council of Australia (ICA) shows that there were similar levels of variability between the losses reported by other insurers [5].

Overall, on the basis of limited information available, it was considered that a margin of about 2 between modelled and observed vulnerabilities should provide a reasonable estimate of the "90 percentile" vulnerability.

\section{Vulnerability Models}

Vulnerability models used in the PML analyses were derived from internationally published data, New Zealand studies [1, 2], data from the 1989 Newcastle earthquake, and limited data on the performance of cavity brick dwellings from the 1968 Meckering earthquake. Models were developed for a range of different building and risk types including brick construction, reinforced concrete and steel frame buildings, frame infill buildings, elevated buildings, various types of dwelling construction, domestic contents, commercial contents and plant, and consequential losses.

Newcastle earthquake loss data were provided by three of the insurance companies who commissioned the initial project for the Sydney region PML. In two cases, a file breakdown of exposures and losses by postcode was provided for domestic and commercial risks, as well as specific information on some 
individual risks. The third company provided details of their total losses, subdivided into risk categories. Information was also obtained from various reports and papers, including details of damage to specific buildings and limited details of domestic losses experienced by other insurers. Although these data were in diverse form, they provided essential information for determining insurance loss levels and to enable calibration of other loss data for Australian conditions. Features noted from the insurance data provided included:

- Differences in interpretations of the extent of damage were apparent. Some of these differences arose from total replacement of part damaged brick elements against the use of "patch" repair; ongoing damage effects from active soil movement; and uncertainty as to the insurer's liability.

- Many older buildings were covered by full replacement policies, with a tendency to take full advantage of replacement in cases of minor damage.

- Many large commercial and industrial buildings and facilities sustained little or no damage, even when located in the higher intensity areas.

Cavity brick construction is common in older residential areas (and near universal in most partstof Perth) and is often used for commercial, industrial, institutional and multi-unit residential buildings. Older brick buildings are particularly vulnerable to earthquake damage and account for much of the damage caused by historical earthquakes. Damage potential is compounded by poor seismic detailing, single brick-width skins, corrosion of cavity ties, deterioration of mortar, and existing cracking. Poor seismic detailing and construction are also evident in newer brick buildings [4, 9]. Newcastle and Meckering data indicate reasonably low damage ratios below MM VII, with damage then increasing rapidly to approach $100 \%$ at MM IX. Masonry infill and partition damage were also consistently evidenced in areas subject to MM VI or higher shaking intensities.

Multi-storey, elevated buildings with open ground floors for carparking are common in many Australian cities. Typically these are small office or multi-unit residential buildings, often with a long, narrow rectangular plan shape. These are classic soft or weak storey structures, which have performed poorly in past earthquakes and are particularly vulnerable at higher intensities.

At the other end of the scale, most high-rise office and residential buildings over 25 - 30 storeys were expected to have a low vulnerability to earthquake forces. Reasons for this include: greater engineering design input; the presence (commonly) of substantial, symmetrically located concrete walls; minimal masonry components; foundations to more competent ground; lower earthquake forces due to dynamic characteristics; and significant wind resistant design measures.

Dwelling losses were found to be negligible below MM V-VI intensity, but rose sharply in areas of MM VII or higher shaking, reflecting the brittle nature of the predominant masonry construction. Edgecumbe, New Zealand [1, 2] data were used as a basis for determining vulnerability values for timber frame dwellings, with margins allowed for inter-event variation and construction differences.

Data from both the Newcastle and Edgecumbe [2] earthquakes indicated similar mean loss ratios for domestic contents, probably reflecting common risk types.

\section{Simulation of Historical Earthquake Losses}

Simulation of recent Australian earthquakes for which insurance loss data were available (ie comparison of actual losses with those predicted by the full risk modei) has generally shown that the loss assessments, including allowance for inter-event variability, cover the reported losses adequately. Limited simulations were performed for the 1981 Appin, 1985 Lithgow, and 1968 Meckering earthquakes.

The recommendation that a repeat of the 1954 Adelaide earthquake be adopted as a minimum prudent PML scenario meant that the simulation of this event was particularly important. It was possible to obtain sufficient loss and exposure data to permit a qualified assessment of the estimated domestic losses. However, very few commercial risks were insured against earthquake damage in Adelaide in 1954

The 1954 earthquake epicentre location is uncertain, magnitude estimates range from M5 to M6, and depth estimates similarly vary. Simulations varying the earthquake magnitude and depth within the estimated ranges resulted in a factor of 3 variation in the insured loss estimate. Accordingly, the model for the Adelaide PML assessment was based on simulation of the reported isoseismal pattern of the 1954 Adelaide earthquake by assumption of an artificial location, magnitude and depth. An M5.2 earthquake, $8 \mathrm{~km}$ deep located at the reported macrocentre was found by sensitivity analysis to best replicate the reported isoseismal pattern. Even so, this model resulted in loss estimates that were higher than the total loss paid by insurance companies. As well as the factor 2 allowed for inter-event variability, the differences could be explained by: higher modelled shaking intensities; soft ground amplification effects conservatively modelled; differences between insurance payouts on indemnity and replacement bases; subsequent geographic spread of exposure encompassing the earthquake centre; allowances for aging and deterioration of the building stock; and the propensity to claim heavily from replacement insurance policies as experienced in Newcastle. The higher estimated loss gives confidence that the modelling was not unconservative.

\section{ANALYSIS}

The analysis method can be visualised as an array of map layers, where the layers represent the geographic, vulnerability, exposure and hazard patterns. A mathematical process works vertically through each layer to arrive at a loss versus shaking intensity relationship for each location. The seismicity is then applied by simulation of multiple earthquake scenarios of different magnitudes, with epicentres located on a grid pattern and exceedance probabilities determined from the parameters for each source zone. The accumulated region loss and event probability are established for each scenario. Results from several tens of thousands of scenarios are combined to determine an overall loss versus probability relationship.

\section{LOSS RESULTS}

The results provided to each company include:

- Probable Maximum Loss (PML) estimates presented in tabular form for specific return periods, and in continuous graphical form, for each of the total, domestic, and commercial risk portfolios (and where required, separations 
into buildings and contents, or other subsets of risk). An example is shown in Figure 3.

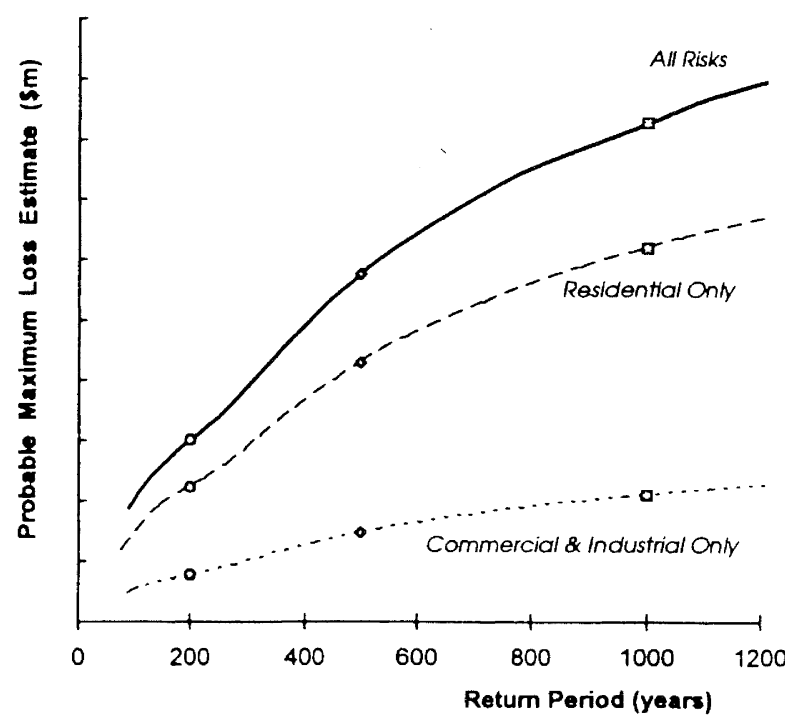

FIGURE 3 Typical PML versus return period relationship

- PML contour maps for specific return period PML values, showing the areas within which the resulting losses from different magnitude earthquakes are expected to exceed the estimated PML. The areas enclosed by the contours also indicate the earthquake source zones that contribute to the PML estimates. Typical example contours for the Perth region are shown in Figure 4.

- Cumulative risk for all Australian regions assessed for the particular insurance company, presented in graphical form of PML against cumulative probability of exceedance per annum. Figure 5 shows an example cumulative risk plot for all regions studied.

\section{CONCLUSIONS}

A viable methodology has been developed for assessing earthquake probable maximum losses for insurance exposures in the main populated regions of Australia. The method includes regional geography, geology, hazards and exposure, and is customised to account for specific exposure characteristics of individual insurance companies. A conservative but justifiable balance has been achieved between the risk of ruin due to underestimate of losses, and a case for obtaining reinsurance without paying excessive premiums.

Overall, the PML percentage losses were generally lower and sometimes markedly lower than the insurance industry perception. This is despite some reasonably conservative assessments of various elements that make up the study. It is significant that the earthquake PML assessments for individual insurance company's can vary by a factor up to 2 according to their exposure "culture". This emphasises the importance of conducting random sample surveys of exposures for each company and the advantages of customised models for each random sample surveys of exposures for each company and the advantages of customised models for each region and individual

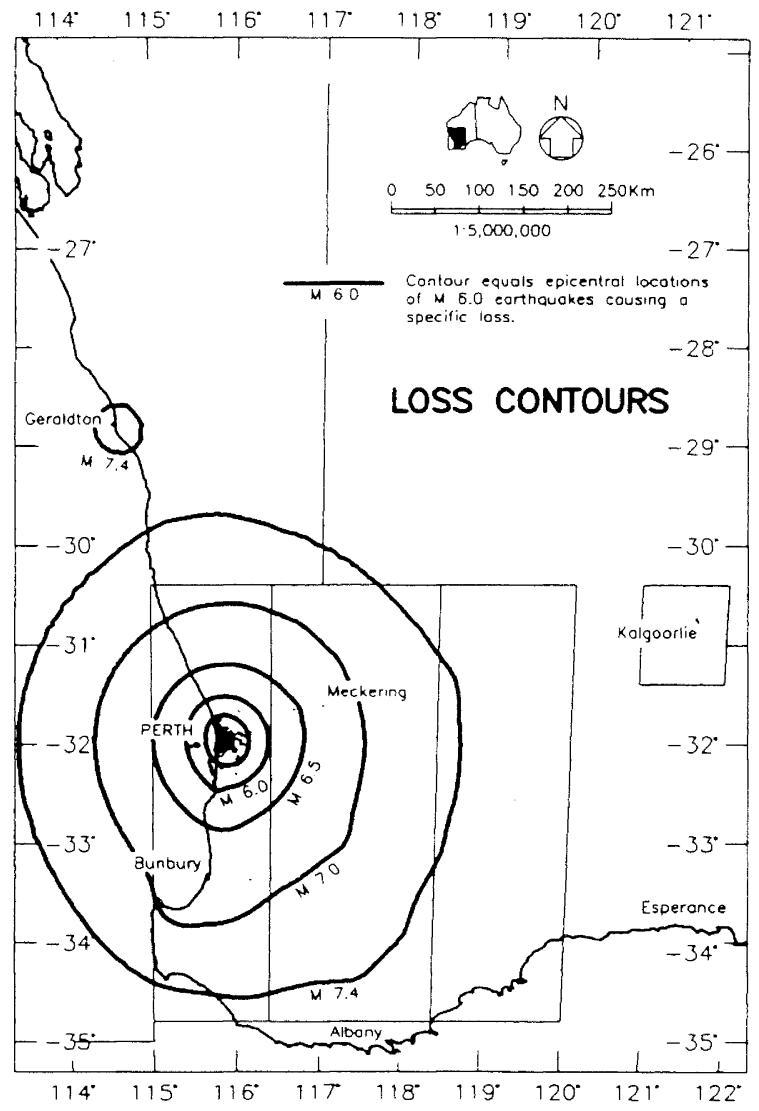

FIGURE 42000 year return period PML contours

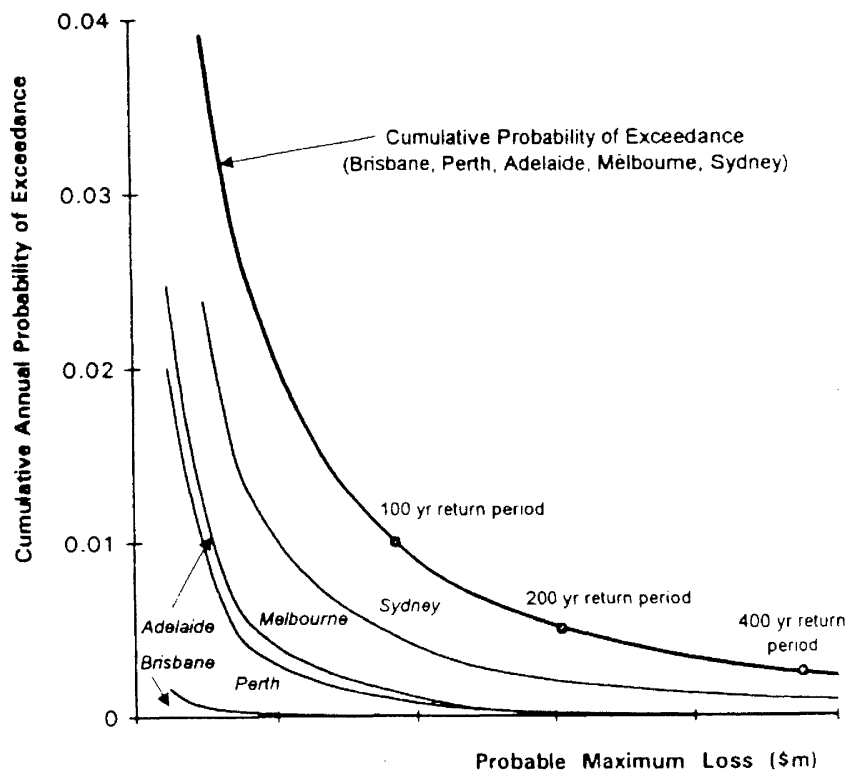

FIGURE 5 Cumulative seismic risk for all regions investigated 
insurers. Identification of significant vulnerabilities and very high individual exposures that are critical contributions to the PML level have also enabled the insurance companies to make adjustments resulting in decreased risks.

\section{ACKNOWLEDGEMENTS}

Approval from Works Consultancy Services Limited and the Australian insurance company clients, AMP General Insurance Ltd, CIC Insurance, Commercial Union Assurance Company, SGIC South Australia, Sun Alliance and Royal Insurance, and Zurich Australian Insurance Ltd who have commissioned PML assessments, is acknowledged. Seismicity data were provided by the Australian Geological Survey Organisation.

\section{REFERENCES}

Much of this presentation is based on client confidential reports in which full acknowledgement is made for the references used. In producing this brief summary of the work, it is not practical to identify all references.

Those with specific reference herein are:

1. Dowrick, D J, 1991. Damage Costs for Houses and Farms as a Function of Intensity in the 1987 Edgecumbe Earthquake. Earthquake Engineering \& Structural Dynamics 20: 445469 .

2. Dowrick, D J and Rhoades, D A, 1990. Damage Ratios for Domestic Buildings in the 1987 Edgecumbe Earthquake. Bulletin of the New Zealand National Society for Earthquake Engineering 23(2): 137-149
3. Gaull, B A, Michael-Leiba, M O, and Rynn, J M W, 1990 Probabilistic Earthquake Risk Maps of Australia. Australian Journal of Earth Sciences 37: 169-187.

4. Institution of Engineers, Australia, 1990. Newcastle Earthquake Study. The Institution of Engineers, Australia

5. Insurance Council of Australia, 1993. Earthquake Claims, Costs and Excesses. Circular No. CO 1597, Victoria, Australia.

6. Rojan, C and Sharpe, R L, 1985. Earthquake Damage Evaluation Data. Applied Technology Council, ATC-13, California.

7. Selby, J and Lindsay, J M, 1982. Engineering Geology of the Adelaide City Area. South Australian Department of Mines and Energy, Bulletin 51, Adelaide, South Australia.

8. Taylor, J K, Thomson, B P and Shepherd, R G, 1974. The Soils and Geology of the Adelaide Area. Geological Survey of South Australia, Department of Mines South Australia, Bulletin 46, Adelaide, South Australia.

9. Tiedemann, H, 1990. Newcastle: The Writing on the Wall. Swiss Reinsurance Co., Zurich. 